\title{
Mercury Thiogermanate Glasses HgS-GeS2: Vibrational, Macroscopic and Electric properties
}

\author{
R. Zaiter, M. Kassem,* M. Bokova, A. Cuisset and E. Bychkov \\ Université du Littoral Côte d'Opale, LPCA, EA CNRS 4493, F-59140 Dunkerque, France
}

\section{Supplementary Information}

Figure S1. X-ray $\mathrm{S}_{\mathrm{x}}(\mathrm{Q})$ structure factor for the $(\mathrm{HgS})_{0.5}(\mathrm{GeS} 2)_{0.5}$ sample measured using highenergy X-ray scattering

Figure S2. X-ray diffraction pattern of the $x=0.55$ composition. The $(\mathrm{HgS})_{0.55}(\mathrm{GeS} 2)_{0.45}$ sample shows Bragg peaks of monoclinic $\mathrm{Hg}_{4} \mathrm{GeS}_{6}$

Figure S3. Temperature dependence of the total electrical conductivity for the $(\mathrm{HgS})_{x}\left(\mathrm{GeS}_{2}\right)_{1-x}$ system. Three groups are clearly seen: glasses, glassy/crystals and monoclinic $\mathrm{Hg}_{4} \mathrm{GeS}_{6}$

Figure S4. Experimental and DFT Raman spectra of (a) glassy $\mathrm{GeS}_{2}$, and (b) corner-sharing CS$\mathrm{Ge}_{2} \mathrm{~S}_{7} \mathrm{H}_{6}$ (green) and edge-sharing ES- $\mathrm{Ge}_{2} \mathrm{~S}_{6} \mathrm{H}_{4}$ (blue) clusters [S1]. The insets show optimized geometries of the clusters. Terminal hydrogen species are omitted, and H-related vibrations are removed from the DFT spectra.

Figure S5. Typical direct fitting of the Raman spectra for two selected glasses in the $(\mathrm{HgS})_{x}\left(\mathrm{GeS}_{2}\right)_{1-x}$ system: (a) $x=0.2$ and (b) $x=0.5$; (c) Raman spectrum of trigonal cinnabar $\alpha-\mathrm{HgS}$ [S2]. The most intense $A_{1}$ symmetric vibrational mode at $256 \mathrm{~cm}^{-1}$ in $\alpha-\mathrm{HgS}$ is shown by the dashed line.

Figure S6. DFT Raman spectra of the (a) boat- and (b) chair-conformers for a $\mathrm{HgGe}_{2} \mathrm{~S}_{10} \mathrm{H}_{8}$ cluster. The insets show optimized geometries of the conformers. Terminal H-species are not shown, H-related vibrations are removed from the spectra. As expected, the chair-conformer is slightly more stable, $\Delta E=-7.62 \mathrm{meV}$. The $A_{1}$ symmetric $\mathrm{Hg}$-S stretching mode is highlighted in light red.

Figure S7. Total neutron correlation functions $T_{\mathrm{N}}(r)$ and Hg-related partial functions $T_{\mathrm{HgS}}(r)$, $T_{\mathrm{HgHg}}(r)$, and $T_{\mathrm{HgGe}}(r)$ for (a) trigonal cinnabar $\alpha-\mathrm{HgS}$, and (b) monoclinic $\mathrm{Hg}_{4} \mathrm{GeS}_{6}$, calculated from the cif files using the XTAL program (http://wwwisis2.isis.rl.ac.uk/disordered/ACH/Software/xtal.htm).

Figure S8. (a) Neutron and X-ray structure factors of equimolar $(\mathrm{HgS})_{0.5}\left(\mathrm{GeS}_{2}\right)_{0.5}$, and (b) the respective $Q$-dependent X-ray weighing coefficients $w_{\mathrm{ij}}^{\mathrm{X}}(Q)$. 
Figure S9. Difference correlation functions $\Delta T(r)$ after subtraction of (a) Hg-S, (b) $\mathrm{Hg}-\mathrm{Hg}$, or (c) Hg-Ge correlations in comparison with $T_{\mathrm{N}}(r)$.

Figure S10. DFT Raman spectra of selected Hg-Ge-S clusters; H-related vibrations are removed from the spectra. The $A_{1}$ symmetric Hg-S stretching mode is highlighted in light red.

Table S1. Spectroscopic parameters (positions $\omega_{i}$, FWHMs and relative areas $A_{i}$ ) obtained by direct Gaussian fitting of the Raman spectra for $(\mathrm{HgS})_{x}\left(\mathrm{GeS}_{2}\right)_{1-x}$ glasses, $0.0 \leq x \leq 0.6$; peak 1 corresponds to the $A_{1}$ symmetric in-phase Hg-S stretching, peak 2: the $A_{1}$ symmetric in-phase Ge-S breathing in $\mathrm{CS}_{-} \mathrm{GeS}_{4 / 2}$ tetrahedra, peak3: the $A_{1}^{c}$ symmetric in-phase Ge-S breathing in ES$\mathrm{GeS}_{4 / 2}$ tetrahedra, peak 4: unresolved feature consisting of multiple contributions, peak 5: the $F_{2}$ asymmetric Ge-S stretching in $\mathrm{ES}^{-\mathrm{GeS}_{4 / 2}}$ tetrahedra. The fitting results are approximate since many complementary contributions were not taken into account, i.e., symmetric out-of-phase and asymmetric Hg-S stretching.

Table S2. Cartesian coordinates for selected optimized DFT clusters.

Table S3. Main experimental and calculated spectral features and assignments. 


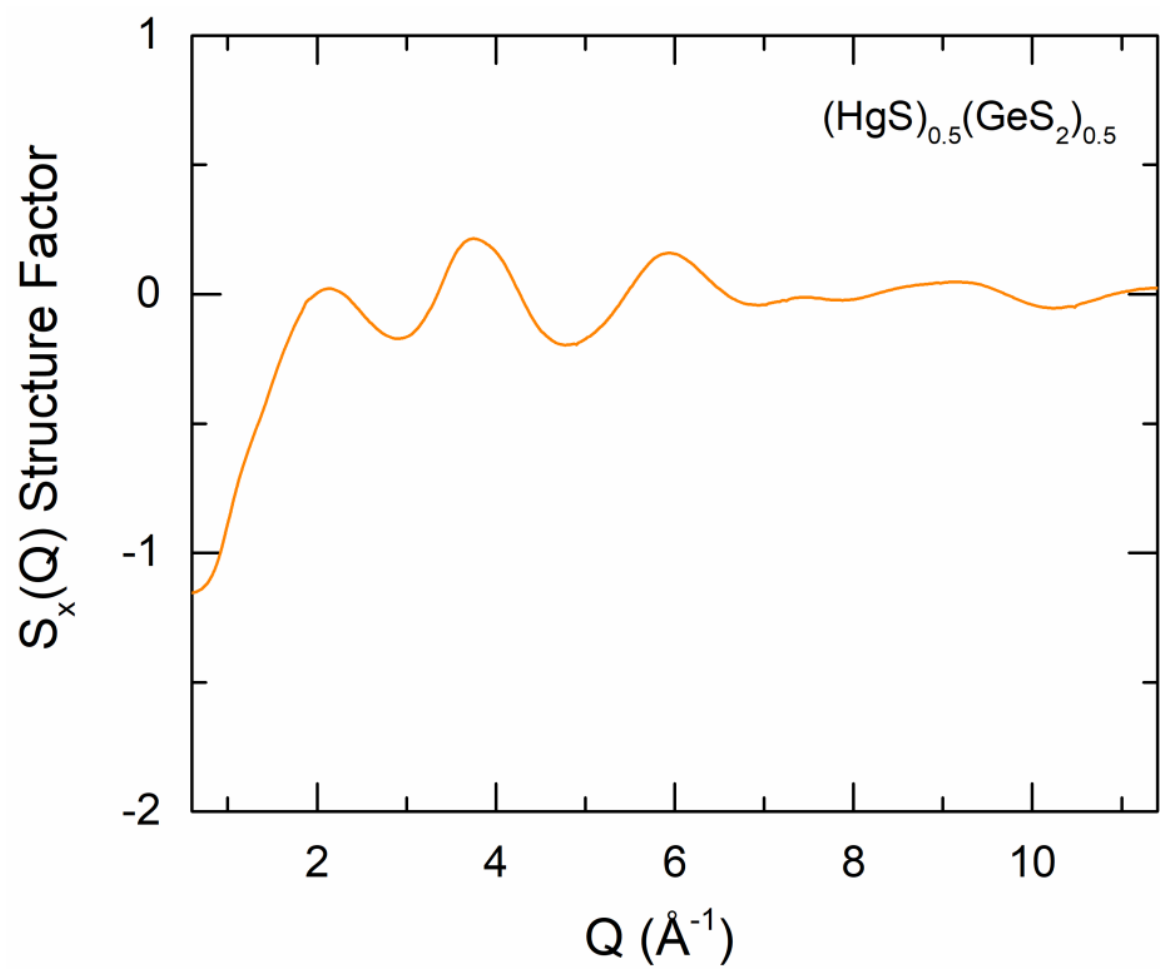

Figure S1. X-ray $\mathrm{S}_{\mathrm{x}}(\mathrm{Q})$ structure factor for the $(\mathrm{HgS})_{0.5}(\mathrm{GeS} 2)_{0.5}$ sample measured using highenergy X-ray scattering 


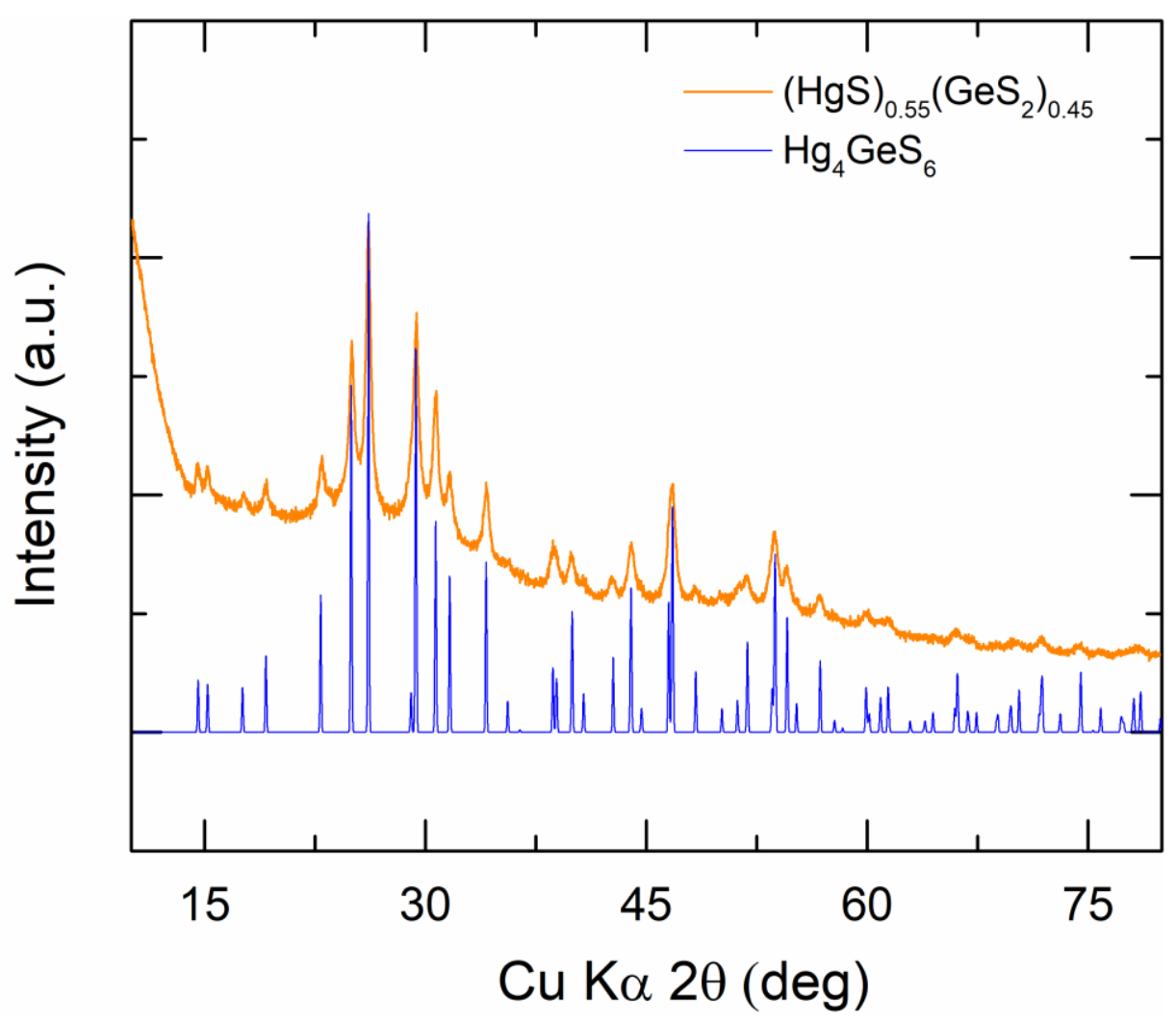

Figure S2. X-ray diffraction pattern of the $x=0.55$ composition. The $(\mathrm{HgS})_{0.55}(\mathrm{GeS} 2)_{0.45}$ sample shows Bragg peaks of monoclinic $\mathrm{Hg}_{4} \mathrm{GeS}_{6}$ 


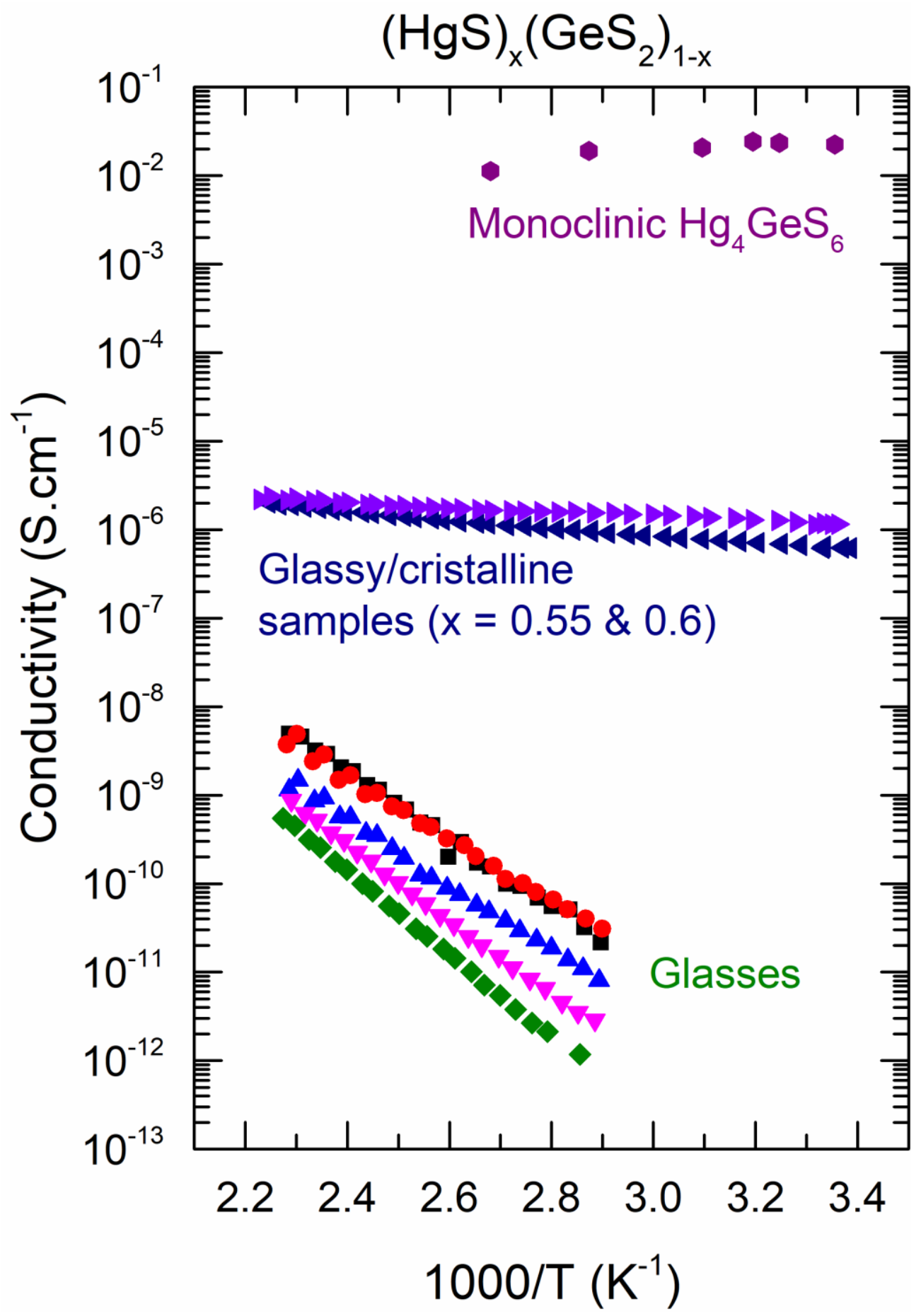

Figure S3. Temperature dependence of the total electrical conductivity for the $(\mathrm{HgS})_{x}\left(\mathrm{GeS}_{2}\right)_{1-x}$ system. Three groups are clearly seen: glasses, glassy/crystals and monoclinic $\mathrm{Hg}_{4} \mathrm{GeS}_{6}$ 


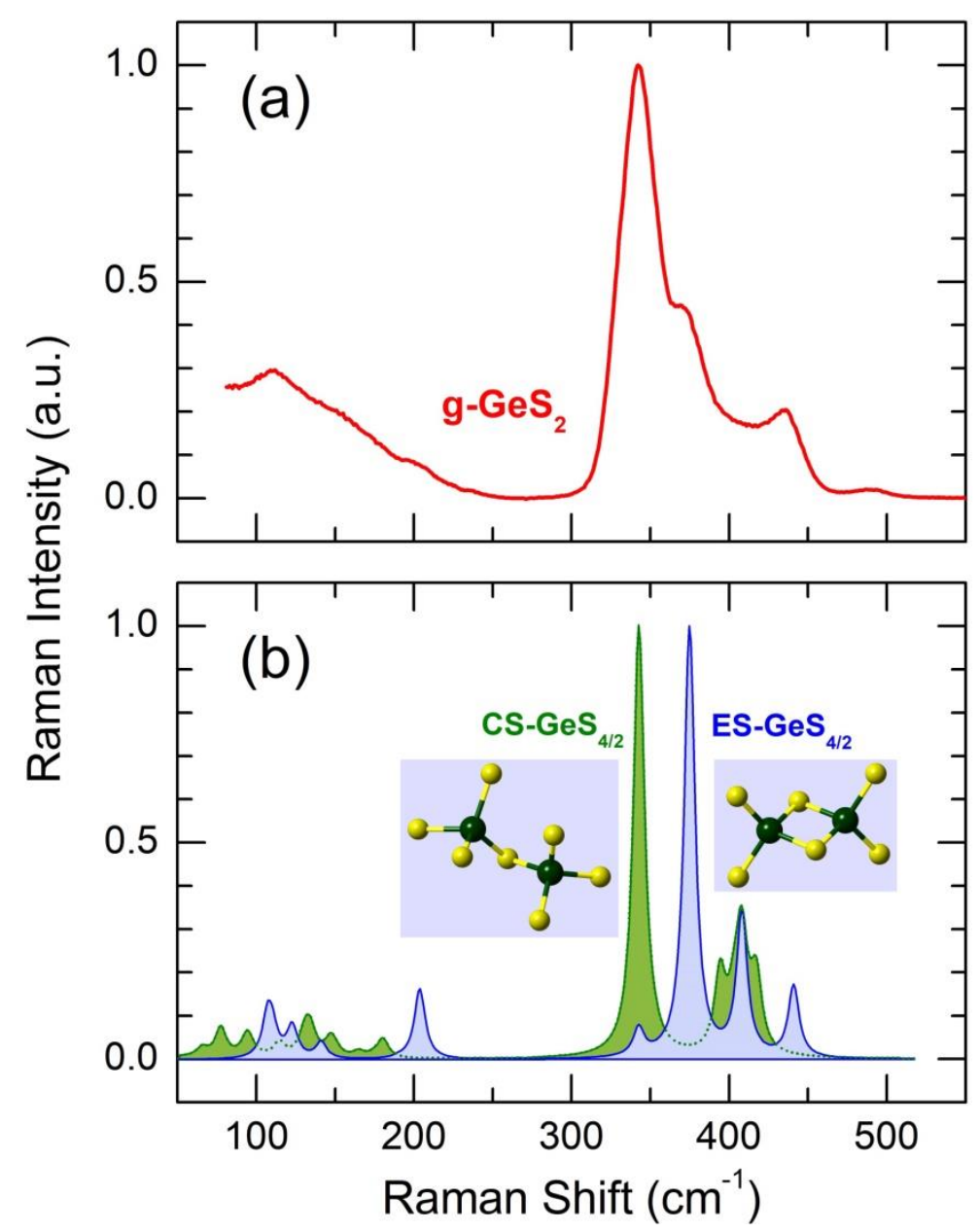

Figure S4. Experimental and DFT Raman spectra of (a) glassy $\mathrm{GeS}_{2}$, and (b) corner-sharing CS$\mathrm{Ge}_{2} \mathrm{~S}_{7} \mathrm{H}_{6}$ (green) and edge-sharing ES- $\mathrm{Ge}_{2} \mathrm{~S}_{6} \mathrm{H}_{4}$ (blue) clusters. ${ }^{\mathrm{S} 1}$ The insets show optimized geometries of the clusters. Terminal hydrogen species are omitted, and H-related vibrations are removed from the DFT spectra.

(S1) P. Masselin, D. Le Coq, A. Cuisset, and E. Bychkov, Spatially resolved Raman analysis of laser induced refractive index variation in chalcogenide glass, Opt. Mater. Express, 2012, 2, 1768-1775. 


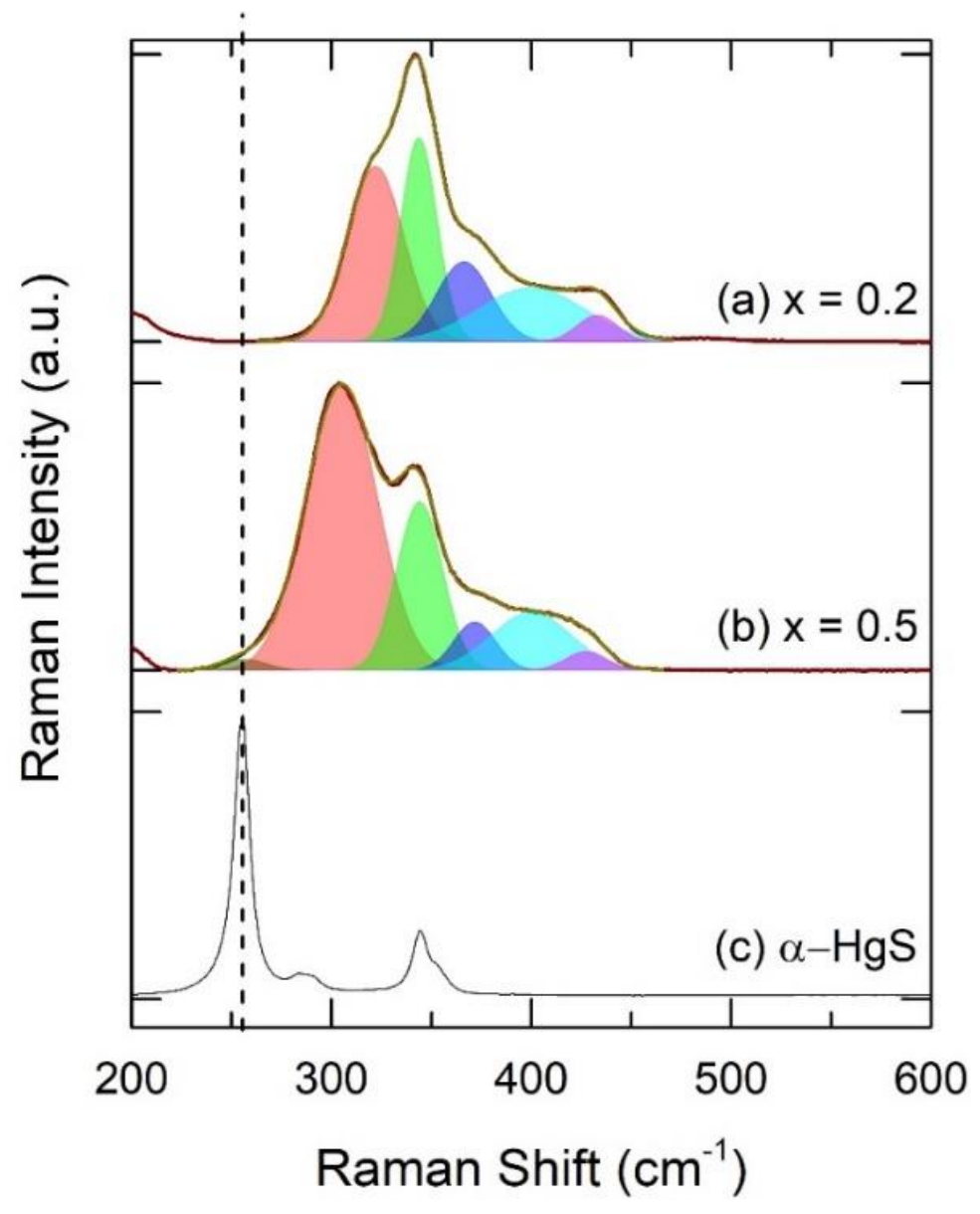

Figure S5. Typical direct fitting of the Raman spectra for two selected glasses in the $(\mathrm{HgS})_{x}\left(\mathrm{GeS}_{2}\right)_{1-x}$ system: (a) $x=0.2$ and (b) $x=0.5$; (c) Raman spectrum of trigonal cinnabar $\alpha-$ HgS. ${ }^{.2}$ The most intense $A_{1}$ symmetric vibrational mode at $256 \mathrm{~cm}^{-1}$ in $\alpha-\mathrm{HgS}$ is shown by the dashed line.

(S2) M. Kassem, S. Khaoulani, A. Cuisset, D. Le Coq, P. Masselin, and E. Bychkov, Mercury Thioarsenate Glasses: A Hybrid Chain/Pyramidal Network. RSC Adv. 2014, 4, 49236-49246. 


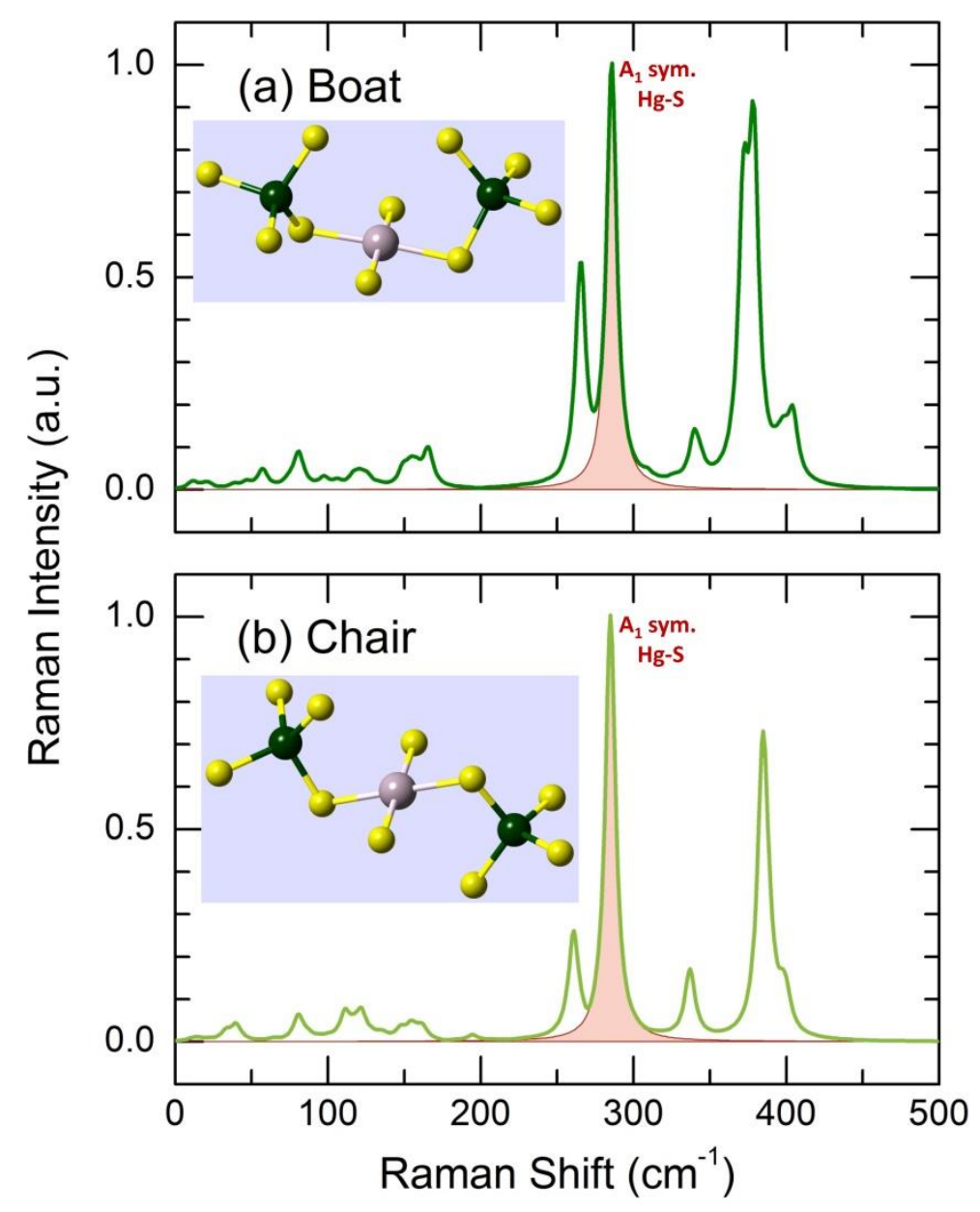

Figure S6. DFT Raman spectra of the (a) boat- and (b) chair-conformers for a $\mathrm{HgGe}_{2} \mathrm{~S}_{10} \mathrm{H}_{8}$ cluster. The insets show optimized geometries of the conformers. Terminal H-species are not shown, H-related vibrations are removed from the spectra. As expected, the chair-conformer is slightly more stable, $\Delta E=-7.62 \mathrm{meV}$. The $A_{1}$ symmetric $\mathrm{Hg}$-S stretching mode is highlighted in light red. 


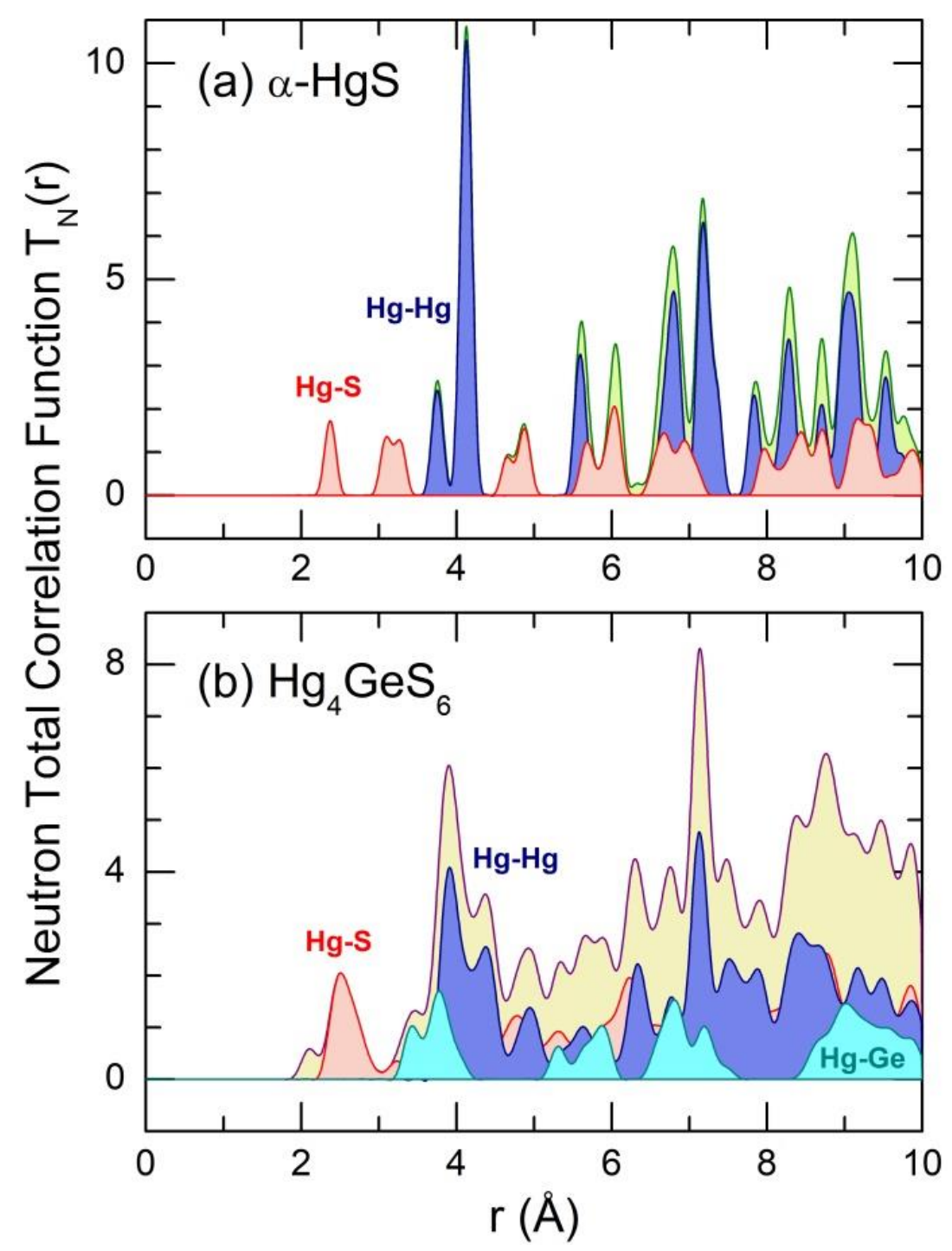

Figure S7. Total neutron correlation functions $T_{\mathrm{N}}(r)$ and Hg-related partial functions $T_{\mathrm{HgS}}(r)$, $T_{\mathrm{HgHg}}(r)$, and $T_{\mathrm{HgGe}}(r)$ for (a) trigonal cinnabar $\alpha-\mathrm{HgS}$, and (b) monoclinic $\mathrm{Hg}_{4} \mathrm{GeS}_{6}$, calculated from the cif files using the XTAL program

(http://wwwisis2.isis.rl.ac.uk/disordered/ACH/Software/xtal.htm).

\section{Agglomeration of $\mathrm{Hg}-\mathrm{S}$ chain-like fragments in equimolar $(\mathrm{HgS})_{0.5}\left(\mathrm{GeS}_{2}\right)_{0.5}$}

A non-random mercury distribution in the studied thiogermanate glasses suggests the formation of Hg-rich entities within the glass network at $x \leq 0.5$. The neutron and X-ray diffraction data taken from Ref. [14] for $(\mathrm{HgS})_{0.5}\left(\mathrm{GeS}_{2}\right)_{0.5}$ was analyzed in order to support or reject this hypothesis. Assuming the simplest case of chain fragments $-\mathrm{S}-\mathrm{Hg}-\mathrm{S}-$ and $-\mathrm{S}-\mathrm{Hg}-\mathrm{S}-\mathrm{Hg}-\mathrm{S}-$, the difference between these two implies the existence of $\mathrm{Hg}$-Hg second intrachain neighbors at a distance of about $3.7 \AA$, as in trigonal cinnabar $\alpha$-HgS, Figure S7. 

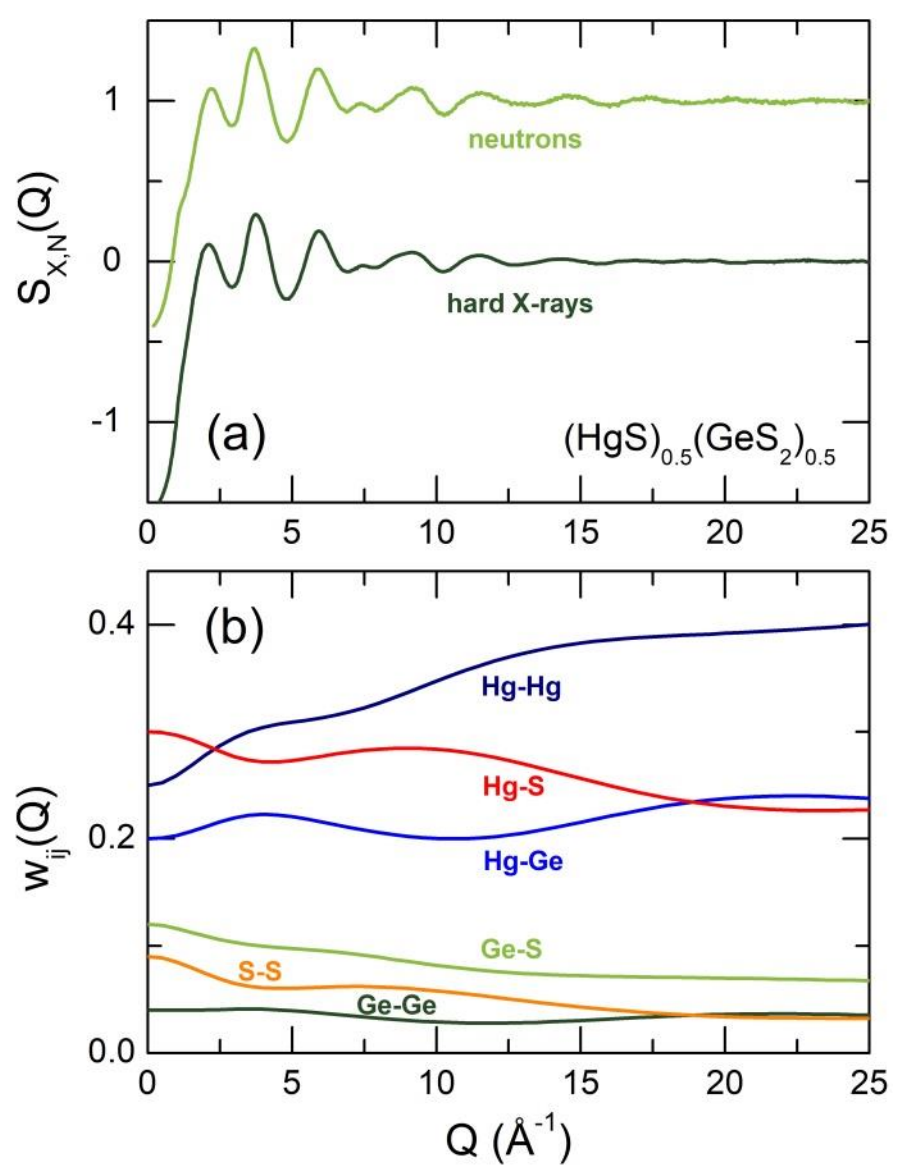

Figure S8. (a) Neutron and X-ray structure factors of equimolar $(\mathrm{HgS})_{0.5}\left(\mathrm{GeS}_{2}\right)_{0.5}$, and (b) the respective $Q$-dependent X-ray weighing coefficients $w_{\mathrm{ij}}^{\mathrm{X}}(Q)$.

The total neutron and X-ray data sets for $(\mathrm{HgS})_{0.5}\left(\mathrm{GeS}_{2}\right)_{0.5}$, Figure S8(a), do not allow to derive 6 partials but using the Faber-Ziman formalism for the neutron and X-ray structure factors:

$S_{\mathrm{N}}(Q)=w_{\mathrm{HgHg}}^{\mathrm{N}} S_{\mathrm{HgHg}}(Q)+w_{\mathrm{HgS}}^{\mathrm{N}} S_{\mathrm{HgS}}(Q)+w_{\mathrm{HgGe}}^{\mathrm{N}} S_{\mathrm{HgGe}}(Q)+w_{\mathrm{GeGe}}^{\mathrm{N}} S_{\mathrm{GeGe}}(Q)+w_{\mathrm{GeS}}^{\mathrm{N}} S_{\mathrm{GeS}}(Q)+$ $w_{\mathrm{SS}}^{\mathrm{N}} S_{\mathrm{SS}}(Q)$,

and

$S_{\mathrm{X}}(Q)=w_{\mathrm{HgHg}}^{\mathrm{X}}(Q) S_{\mathrm{HgHg}}(Q)+w_{\mathrm{HgS}}^{\mathrm{X}}(Q) S_{\mathrm{HgS}}(Q)+w_{\mathrm{HgGe}}^{\mathrm{X}}(Q) S_{\mathrm{HgGe}}(Q)+w_{\mathrm{GeGe}}^{\mathrm{X}}(Q) S_{\mathrm{GeGe}}(Q)+$ $w_{\mathrm{GeS}}^{\mathrm{X}}(Q) S_{\mathrm{GeS}}(Q)+w_{\mathrm{SS}}^{\mathrm{X}}(Q) S_{\mathrm{SS}}(Q)$,

we can subtract any of the six partials at a time. We should also take into account that the X-ray weighting coefficients $w_{\mathrm{ij}}^{\mathrm{X}}(Q)$ are $Q$-dependent, Figure S8(b), where the scattering vector $Q=$ $\frac{4 \pi \sin \theta}{\lambda}$ is related to the scattering angle $\theta$ and the incident radiation wavelength $\lambda$. 


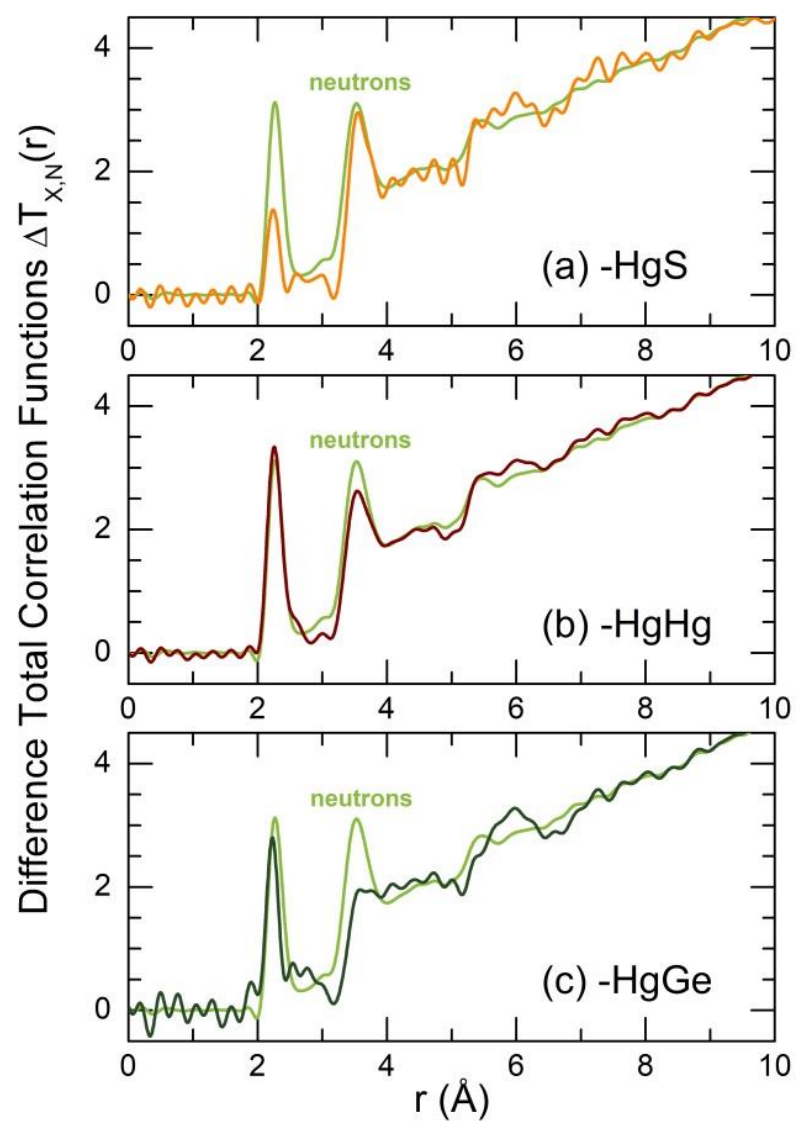

Figure S9. Difference correlation functions $\Delta T(r)$ after subtraction of (a) $\mathrm{Hg}-\mathrm{S}$, (b) $\mathrm{Hg}-\mathrm{Hg}$, or (c) Hg-Ge correlations in comparison with $T_{\mathrm{N}}(r)$.

Subtracting any of the six correlations, one obtains the difference structure factor $\Delta S(Q)$, taking as an example subtraction of the Hg-Hg correlations:

$$
\Delta S_{-\mathrm{HgHg}}(Q)-1=\left\{\left[S_{\mathrm{X}}(Q)-1\right]-\frac{W_{\mathrm{HgHg}}^{\mathrm{X}}(Q)}{W_{\mathrm{HgHg}}^{\mathrm{N}}}\left[S_{\mathrm{N}}(Q)-1\right]\right\} \frac{W_{\mathrm{GeS}}^{\mathrm{X}}(Q)}{W_{\mathrm{GeS}}^{\mathrm{X}}(Q)-\frac{W_{\mathrm{HgHg}}^{\mathrm{X}}(Q)}{W_{\mathrm{HgHg}}^{N}} W_{\mathrm{GeS}}^{\mathrm{N}}} .
$$

The right hand part of Equation (3) normalizes the difference structure factor to the original, before subtraction, Ge-S correlations.

The Fourier transform of $\Delta S(Q)$ s yields the difference correlation functions in $r$-space, $\Delta T(r)$, shown in Figure $\mathbf{S 9}$ in comparison with the total neutron correlation function $T_{\mathrm{N}}(r)$. As expected, the Hg-S subtraction decreases significantly the peak at $2.24 \AA$ corresponding to Ge-S and Hg-S nearest neighbors; the second neighbor peak at $3.6 \AA$ reveals minor changes. On the contrary, the Hg-Hg subtraction decreases the second neighbor peak, all other changes are rather negligible. Finally, the Hg-Ge subtraction decreases significantly the second neighbor peak, also shifting it to higher $r$. Comparing the derived results with partial correlation functions in trigonal $\alpha-\mathrm{HgS}$ and monoclinic $\mathrm{Hg}_{4} \mathrm{GeS}_{6}$, Figure S7, we conclude the presence of a non-negligible fraction of $\mathrm{Hg}$-Hg second intrachain neighbors at about $3.7 \AA$, the absence or a weak fraction of interchain $\mathrm{Hg}-\mathrm{Hg}$ correlations at $4.1 \AA$, and strong $\mathrm{Hg}$-Ge second neighbor contacts. This information cannot be used for precise quantitative description since the derived difference functions are not the properly defined partials. Nevertheless, it is consistent with the hypothesis that mercury distribution, at least, in equimolar $(\mathrm{HgS})_{0.5}\left(\mathrm{GeS}_{2}\right)_{0.5}$, is non-random and Hg-S related oligomeric chain fragments are present in mercury thiogermanate glasses. An AIMD modeling is planned in the nearest future but it easily takes several months caused by heavy first-principle simulations. 


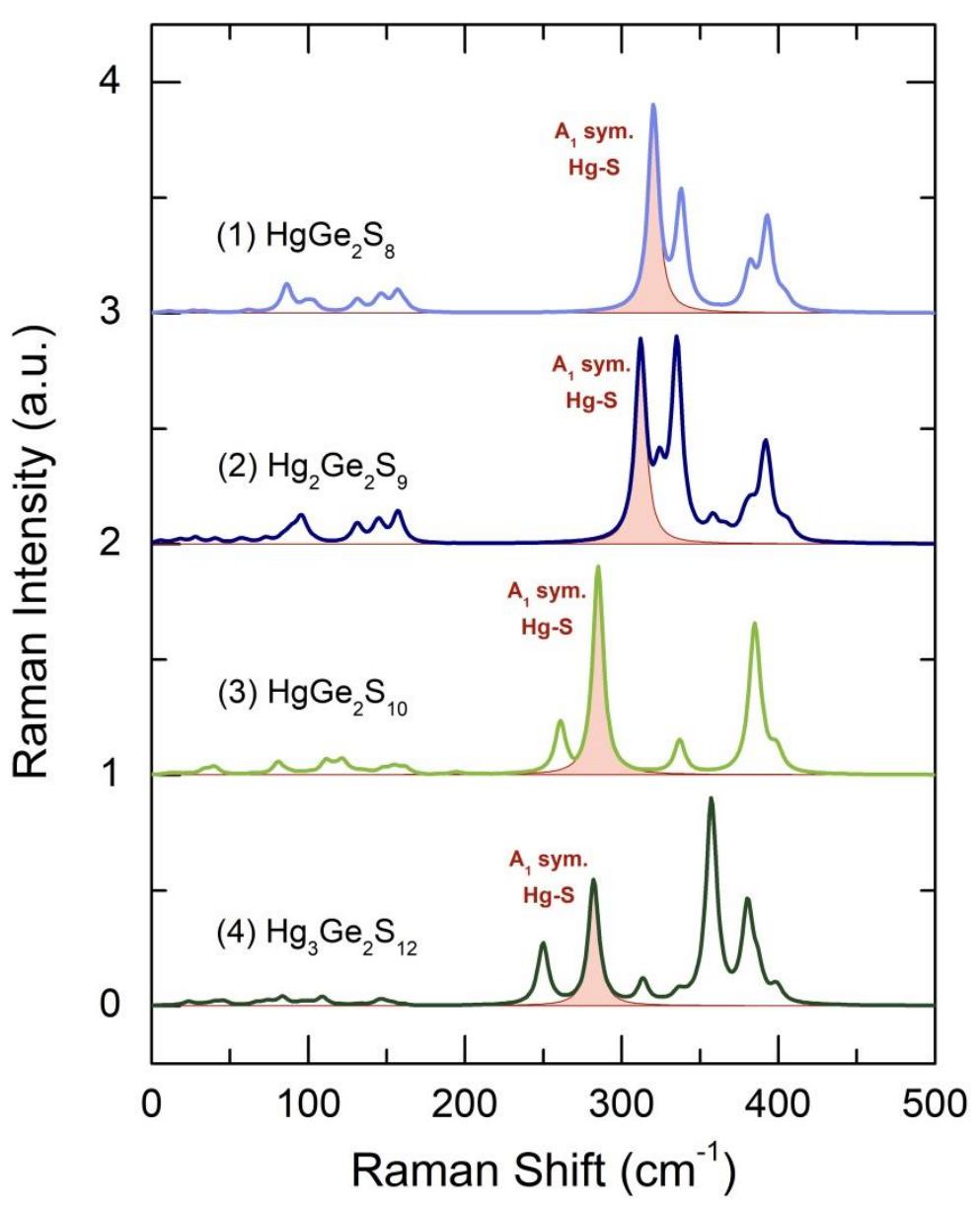

Figure S10. DFT Raman spectra of selected Hg-Ge-S clusters; H-related vibrations are removed from the spectra. The $A_{1}$ symmetric Hg-S stretching mode is highlighted in light red. 
Table S1. Spectroscopic parameters (positions $\omega_{i}$, FWHMs and relative areas $A_{i}$ ) obtained by direct Gaussian fitting of the Raman spectra for $(\mathrm{HgS})_{x}\left(\mathrm{GeS}_{2}\right)_{1-x}$ glasses, $0.0 \leq x \leq 0.6$; peak 1 corresponds to the $A_{1}$ symmetric in-phase Hg-S stretching, peak 2: the $A_{1}$ symmetric in-phase Ge-S breathing in $\mathrm{CS}_{-} \mathrm{GeS}_{4 / 2}$ tetrahedra, peak3: the $A_{1}^{c}$ symmetric in-phase Ge-S breathing in $\mathrm{ES}_{-\mathrm{GeS}} \mathrm{S}_{4 / 2}$ tetrahedra, peak 4: unresolved feature consisting of multiple contributions, peak 5: the $F_{2}$ asymmetric Ge-S stretching in ES-GeS $4 / 2$ tetrahedra. The fitting results are approximate since many complementary contributions were not taken into account, i.e., symmetric out-of-phase and asymmetric Hg-S stretching.

\begin{tabular}{|c|c|c|c|c|c|c|c|c|c|c|c|c|c|c|c|}
\hline & \multicolumn{3}{|c|}{1} & \multicolumn{3}{|c|}{2} & \multicolumn{3}{|c|}{3} & \multicolumn{3}{|c|}{4} & \multicolumn{3}{|c|}{5} \\
\hline \multicolumn{16}{|c|}{$\left(\mathrm{HgS}_{x}\left(\mathrm{GeS}_{2}\right)_{1-x}\right.$} \\
\hline$x$ & $\omega_{1}$ & FWHM & $\mathbf{A}_{1}$ & $\omega 2$ & FWHM & $\mathbf{A}_{2}$ & $\omega_{3}$ & FWHM & $\mathbf{A}_{3}$ & $\omega_{4}$ & FWHM & $\mathbf{A}_{4}$ & $\omega_{5}$ & FWHM & $\mathbf{A}_{5}$ \\
\hline 0.0 & & & & 342.3 & 28.9 & 30.0 & 372.9 & 23.0 & 8.0 & 400.0 & 44.1 & 8.5 & 436.1 & 27.5 & 4.9 \\
\hline 0.1 & 328.0 & 31.5 & 16.4 & 344.2 & 22.2 & 15.8 & 368.9 & 30.1 & 11.5 & 406.5 & 60.3 & 11.9 & 436.2 & 21.0 & 2.3 \\
\hline 0.2 & 322.1 & 33.1 & 21.6 & 343.8 & 21.3 & 16.0 & 366.2 & 31.9 & 9.4 & 400.0 & 62.6 & 12.5 & 433.0 & 23.7 & 2.3 \\
\hline 0.3 & 316.6 & 35.3 & 30.5 & 343.2 & 21.2 & 15.5 & 365.8 & 39.5 & 13.6 & 409.9 & 51.8 & 10.8 & 433.6 & 18.6 & 1.1 \\
\hline 0.4 & 310.9 & 38.2 & 40.7 & 343.8 & 23.8 & 18.1 & 369.6 & 30.5 & 8.4 & 403.5 & 49.0 & 11.9 & 430.6 & 23.7 & 2.0 \\
\hline 0.5 & 305.6 & 44.4 & 46.7 & 344.1 & 24.5 & 14.3 & 369.6 & 28.7 & 6.0 & 400.9 & 46.1 & 9.7 & 427.5 & 24.6 & 1.7 \\
\hline 0.6 & 303.8 & 47.7 & 49.8 & 343.0 & 23.3 & 11.2 & 368.4 & 36.7 & 8.5 & 403.1 & 37.2 & 6.3 & 426.1 & 23.3 & 1.5 \\
\hline
\end{tabular}


Table S2. Cartesian coordinates for selected optimized DFT clusters.

\begin{tabular}{|c|c|c|c|c|}
\hline Cluster & Atom & $\mathrm{X}$ & Y & $\mathrm{Z}$ \\
\hline \multirow{7}{*}{$\mathrm{Hg}_{2} \mathrm{~S}_{3} \mathrm{H}_{2}$} & $\mathrm{Hg}$ & -0.405004 & 0.610844 & 0.000062 \\
\hline & $\mathrm{S}$ & -2.765921 & 0.611009 & 0.000099 \\
\hline & $S$ & 1.947420 & 0.450139 & 0.000042 \\
\hline & $\mathrm{H}$ & -2.865018 & 1.954462 & -0.000429 \\
\hline & $\mathrm{Hg}$ & 2.511601 & 2.738389 & 0.000339 \\
\hline & $\mathrm{S}$ & 3.124772 & 5.018571 & 0.000715 \\
\hline & $\mathrm{H}$ & 4.447607 & 4.764067 & -0.000828 \\
\hline \multirow{17}{*}{$\mathrm{HgGe}_{2} \mathrm{~S}_{8} \mathrm{H}_{6}$} & $\mathrm{Hg}$ & -0.646160 & 0.854703 & 0.046725 \\
\hline & $\mathrm{S}$ & -2.965620 & 0.809762 & 0.523110 \\
\hline & $\mathrm{S}$ & 1.670354 & 1.000191 & -0.423838 \\
\hline & $\mathrm{Ge}$ & -3.725535 & 0.084261 & -1.443371 \\
\hline & $\mathrm{Ge}$ & 2.478232 & 0.102325 & 1.450210 \\
\hline & $\mathrm{S}$ & -5.861163 & 0.784612 & -1.452812 \\
\hline & $\mathrm{H}$ & -6.197204 & 0.045900 & -2.527609 \\
\hline & S & -3.465359 & -2.145974 & -1.562967 \\
\hline & $\mathrm{H}$ & -3.681160 & -2.200335 & -2.891954 \\
\hline & $S$ & -2.578435 & 0.869741 & -3.226722 \\
\hline & $\mathrm{H}$ & -3.101989 & 2.107966 & -3.142090 \\
\hline & $\mathrm{S}$ & 4.570628 & 0.917572 & 1.542817 \\
\hline & $\mathrm{H}$ & 4.952819 & 0.082926 & 2.528267 \\
\hline & S & 2.345384 & -2.138385 & 1.317338 \\
\hline & $\mathrm{H}$ & 2.567600 & -2.329597 & 2.632555 \\
\hline & $\mathrm{S}$ & 1.295787 & 0.615208 & 3.308096 \\
\hline & $\mathrm{H}$ & 1.747136 & 1.883105 & 3.364478 \\
\hline \multirow{19}{*}{$\mathrm{Hg}_{2} \mathrm{Ge}_{2} \mathrm{~S}_{9} \mathrm{H}_{6}$} & $\mathrm{Hg}$ & -4.083099 & 3.453621 & 2.765600 \\
\hline & $S$ & -5.461103 & 3.245399 & 4.686722 \\
\hline & $\mathrm{S}$ & -2.804156 & 3.803031 & 0.820864 \\
\hline & $\mathrm{Hg}$ & -0.756320 & 2.921371 & 1.567739 \\
\hline & $\mathrm{S}$ & 1.337802 & 1.977766 & 2.162448 \\
\hline & Ge & 1.956753 & 3.409080 & 3.751624 \\
\hline & $\mathrm{Ge}$ & -5.096269 & 1.097639 & 5.151095 \\
\hline & $\mathrm{S}$ & -6.432055 & -0.174905 & 3.864073 \\
\hline & $\mathrm{H}$ & -5.789383 & -1.323153 & 4.154393 \\
\hline & $\mathrm{S}$ & -3.010358 & 0.375398 & 4.650083 \\
\hline & $\mathrm{H}$ & -2.424235 & 1.021185 & 5.676888 \\
\hline & $\mathrm{S}$ & -5.511222 & 0.963344 & 7.355436 \\
\hline & $\mathrm{H}$ & -5.490193 & -0.383182 & 7.374423 \\
\hline & $\mathrm{S}$ & 2.156697 & 5.567591 & 3.133201 \\
\hline & $\mathrm{H}$ & 3.262785 & 5.354747 & 2.394649 \\
\hline & $\mathrm{S}$ & 3.931190 & 2.585207 & 4.438541 \\
\hline & $\mathrm{H}$ & 4.191444 & 3.639568 & 5.234858 \\
\hline & $\mathrm{S}$ & 0.332408 & 3.453561 & 5.319482 \\
\hline & $\mathrm{H}$ & 0.747242 & 4.601908 & 5.888449 \\
\hline
\end{tabular}


Table S3. Main experimental and calculated spectral features and assignments.

\begin{tabular}{|c|c|c|}
\hline $\begin{array}{l}\text { Experimental frequency } \\
\qquad\left(\mathrm{cm}^{-1}\right)\end{array}$ & $\begin{array}{l}\text { DFT frequency } \\
\qquad\left(\mathrm{cm}^{-1}\right)\end{array}$ & Assignment \\
\hline \multirow{2}{*}{$300-328$} & 306-320 (2-fold Hg) & \multirow{2}{*}{ Symmetric Hg-S stretching } \\
\hline & 282-285 (4-fold Hg) & \\
\hline $342-344$ & 343 & $\begin{array}{l}\text { Symmetric Ge-S breathing in } \\
\text { corner-sharing CS-GeS } \\
4 / 2\end{array}$ \\
\hline $366-373$ & 375 & $\begin{array}{l}\text { Symmetric Ge-S breathing in } \\
\text { edge-sharing ES-GeS }\end{array}$ \\
\hline $397-406$ & $382-408$ & $\begin{array}{l}\text { Multiple Ge-S stretching } \\
\text { modes in GeS } \\
\text { connected tetrahedra } \\
\text { to mercury units }\end{array}$ \\
\hline $426-436$ & 441 & $\begin{array}{l}\text { Asymmetric Ge-S stretching in } \\
\text { edge-sharing ES-GeS }\end{array}$ \\
\hline
\end{tabular}

